\title{
Tangence
}

\section{Le tour de la bibliothèque, le tour du monde ( L'art de voyager , de Normand Doiron)}

\section{Robert Dion}

Numéro 49, décembre 1995

Les littératures francophones de l'Afrique et des Antilles

URI : https://id.erudit.org/iderudit/025881ar

DOI : https://doi.org/10.7202/025881ar

Aller au sommaire du numéro

Éditeur(s)

Tangence

ISSN

0226-9554 (imprimé)

1710-0305 (numérique)

Découvrir la revue

Citer ce compte rendu

Dion, R. (1995). Compte rendu de [Le tour de la bibliothèque, le tour du monde (

L'art de voyager , de Normand Doiron)]. Tangence, (49), 113-118.

https://doi.org/10.7202/025881ar d'utilisation que vous pouvez consulter en ligne.

https://apropos.erudit.org/fr/usagers/politique-dutilisation/ 


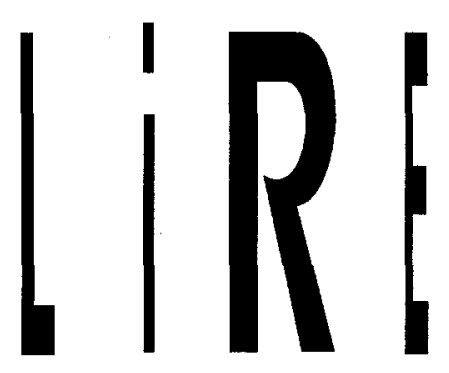

\title{
Le tour de la bibliothèque, le tour du monde Normand Doiron, L'art de voyager. Le déplacement à l'âge classique, Québec/Paris, Presses de l'Univer- sité Laval/Klincksieck, 1995, 258 p.
}

\begin{abstract}
Ainsi que les livres emprisonnaient les premiers humanistes, le monde se referme sur le voyageur romantique, et seul le rêve lui permettra de s'évader. (p. 199)
\end{abstract}

On s'en doutait bien: la vogue du récit de voyage - dont l'engouement pour la collection "Payot/Voyageurs" et les livres de Chatwin, Bouvier, Maillart, etc., est actuellement l'indice éclatant - n'est pas nouvelle et remonte à loin, au moins à la Renaissance. Elle est liée à celle du "voiage" lui-même, mode de déplacement et de figuration du déplacement opposé tant au pèlerinage médiéval qu'à "l'errance des âges obscurs" ${ }^{1}$. C'est précisément l'émergence de la notion de voyage et des théories classiques du déplacement consignées dans les arts de voyager (peu ou prou analogues aux arts poétiques qui gouvernent les autres genres littéraires) qu'observe Normand Doiron dans son ouvrage sur les pérégrinations aux $\mathrm{XVI}^{\mathrm{e}}$ et $\mathrm{XvII}^{\mathrm{e}}$ siècles. En trois parties respectivement intitulées "Voyage et Humanisme ", "Voyage et Rhétorique" et "Voyage et Poétique", il s'attache à définir le contenu conféré à la notion de voyage par les humanistes renaissants, puis à dégager la rhétorique qui émerge en même

1 Normand Doiron, L'art de toyager, p. 2. Les références à cet ouvrage seront désormais signalées par le folio entre parenthèses. 
temps que cette notion (spécialement celle que les jésuites prêtèrent aux "Sauvages" du Canada dans les Relations), et enfin à mettre en évidence les structures du récit de voyage, qui s'organisent autour des moments clefs du parcours: départ, épreuve et retour. Refonte d'une thèse de doctorat et de quelques articles, l'essai de Doiron représente à mon sens — je l'indique d'emblée - un livre passionnant, finement érudit, bellement écrit, qui convaincra certainement le non-spécialiste, simple amateur de récits de voyage, si ce n'est le seiziémiste et le dix-septièmiste: car je n'ose ici me prononcer pour ces derniers sur la nouveauté et sur l'originalité des thèses défendues par l'auteur ${ }^{2}$, si bien que je me contenterai de simplement suivre son itinéraire afin d'en montrer le clair (et classique) ordonnancement.

Suivant Doiron, les humanistes de la Renaissance inventent le voyage moderne sans en avoir parfaitement conscience, en croyant imiter les Anciens, en particulier l'Odyssée et l'Énéide. Des exploits d'Ulysse et d'Énée, ils retiennent l'idée de périple, de grand tour, en somme de tour et de retour. Tout comme les héros antiques, le voyageur humaniste est un être sédentaire qui s'arrache (ou qu'on arrache) à son pays et qui vise à y revenir (Ulysse) ou à fonder une nouvelle patrie si, d'aventure, le retour se révélait impossible (Énée); mais à la différence de ces derniers, il n'est pas exilé de sa terre natale, et ses pérégrinations sont axées vers un but: l'agréable et, surtout, l'utile. On voyage désormais pour se former, pour glaner là où ils se trouvent les plus beaux fleurons de la culture. L'humaniste élabore une pédagogie du voyage qui n'admet pas l'errance caractéristique des héros d'Homère et de Virgile ${ }^{3}$; Juste Lipse, un érudit flamand du $\mathrm{XvI}^{\mathrm{e}}$ siècle, conçoit ainsi le déplacement raisonné "comme un art qui permettra de faire le tour du monde moderne" (p. 25) et, ce faisant, d'apprendre la vertu, la prudence et la sagesse. Le déplacement est "une méthode d'ordonnance et de classification du monde" (p. 29) - "méthode" étant formé du préfixe grec meta et du terme hodos, qui signifie "route" -, un chemin tracé avec précision (la métaphore du cbemin est fondamentale); chez

2 Quoique les lieux de publication des divers articles repris dans l'ouvrage Littérature, Revue des sciences bumaines, xvif siècle, etc. - témoignent éloquemment de leur qualité.

3 Que ces héros antiques errant de par le monde soient tout de même devenus les modèles des voyageurs au $\mathrm{xvr}^{\mathrm{e}}$ siècle manifeste bien, d'après Doiron, le travail d'interprétation des humanistes (p. 67). 
Descartes, par exemple, "L'art de voyager devient un modèle discursif, une méthode que doit suivre tout esprit qui recherche" (p. 64): errer, c'est forcément faire erreur. Ainsi, au même titre que le discours, le déplacement dans l'espace est tenu de respecter les règles d'une stricte dispositio (p. 29): tous deux sont soumis à la scansion de la période - periodos voulant dire "circuit".

Le lien entre voyage et langage est premier: pour le voyageur, écrit Doiron, “le monde est d'abord un livre dont il faut trouver le sens" (p. 17). Le progrès réside dans la progression; et lespace se substitue au temps comme élément d'une nouvelle épistémologie historique. Mais, puisque le monde s'assimile à un livre, on ne s'étonnera pas qu'il tende peu à peu à le remplacer. C'est ainsi que les voyageurs se donnent préséance sur les philosophes et prétendent que la connaissance de l'univers passe d'abord par l'expérience (experientia est rerum magistra) et non par les livres:

L'expérience ébranle les autorités de l'humanisme savant, non seulement le péripatétisme officiel, mais le dogme de la "majorité" des Anciens. Et pourtant les voyageurs retournent à la pédagogie du livre, à l'enseignement du magister. Il n'échappent pas à la passion qu'ils condamnaient comme un vice au moment du départ. Ils ne résistent pas à ce besoin d'écrire à leur tour des livres, les récits de leurs voyages. (p. 52)

Professant une morale de l'expérience, les voyageurs plaident en faveur d'une connaissance certes susceptible de se déposer dans les livres, mais dénuée de la rhétorique livresque - dénudée.

C'est seulement au xvir ${ }^{\mathrm{e}}$ siècle que le récit de voyage humaniste "est pleinement reconnu comme le genre littéraire assurant la représentation classique du déplacement dans l'espace" (p. 61), c'est-à-dire comme une moderne épopée en prose (au même moment toutefois, il doit faire face à la concurrence du voyage galant, dont l'un des plus prestigieux représentants est La Fontaine, et qui menace de l'engager sur la voie du romanesque ${ }^{4}$ ). Les arts de voyager classiques déterminent trois modes de déplacement: le voyage, l'errance et la promenade, avec une nette prédilection pour le premier, qui figure le "droit chemin". Dans leur volonté d'atteindre l'universelle humanité, les voyageurs

4 Ce qui va effectivement se produire: pensons à tous les romans des xviI et $\mathrm{xvu}^{\mathrm{C}}$ siècles qui affectent la forme du récit de voyage. 
116

n'improvisent pas, ils ne se contentent pas de noter leurs impressions; ils participent à l'entreprise commune de forger une poétique du voyage en "formul[ant] des préceptes, des réflexions sur le sens de leur déplacement. Ils citent leurs devanciers, les approuvent ou les réfutent, peu importe, ils le font au nom de principes sur la manière de voyager ou d'écrire un voyage." (p. 88).

Nettement plus courte que la première et d'une teneur autre, la deuxième partie de l'ouvrage fait apparaître les liens entre récit de voyage et rhétorique au moyen d'une analyse des discours prétendument tenus par les "Sauvages" et rapportés par les pères Lejeune et Brébeuf surtout. Doiron prend prétexte de cette analyse pour relater la "genèse des représentations de l'éloquence sauvage" ( $p$. 117) et, plus largement, pour montrer le rôle qu'ont joué ces relations dans la renaissance de la rhétorique de Tacite en France à l'âge classique ${ }^{5}$ :

[...] c'est au moment où les contraintes de la monarchie deviennent incontournables, où les robins [les représentants de la noblesse de robe] reconnaissent comme impossible en France la grande éloquence délibérative, et Montaigne avait déjà perdu cette illusion, que naît l'idéal rhétorique d'une éloquence sauvage servant une démocratie à l'antique. (p. 118)

La rhétorique toute nue des Sauvages, modèle cohérent d'un classicisme primitif (p. 130), constitue l'avatar fantasmé d'une rhétorique idéale (à l'usage des Européens) que les jésuites voudraient réintroduire; les Relations feront ainsi largement état des qualités de cette éloquence, de son style "ténu" (p. 127) - tout de simplicité, d'humilité et de gravité - , de sa prudence et de sa ferveur.

Visant à dégager les structures discursives qui reproduisent les grands moments du parcours, la troisième et dernière partie du livre de Doiron fait état des rituels du départ, de la tempête en mer et du retour. D'abord, l'expérience du départ est celle de l'altérité, de la séparation qui ouvre sur l'espace du voyage; sur le plan poétique, elle marque l'origine du récit (p. 149). Le départ signifie une disparition (souhaitée provisoire) du voyageur, à

5 "Les jésuites découvrent progressivement dans les Relations une formule stylistique originale leur permettant de rattacher à la tradition latine de l'éloquence leur participation à l'histoire héroïque de la Nouvelle-France." (p. 136). 
laquelle le retour viendra mettre un terme; il constitue un authentique acte sacré, ce qui explique le caractère religieux des rituels qui l'accompagnent, rituels chargés de donner à celui qui s'apprête à quitter sa communauté "un témoignage solennel de son appartenance, un avertissement contre la tentation d'un retour régressif à la vie vagabonde" (p. 153). Une autre tentation du voyageur consiste à se laisser envahir par l'altérité, ce que prescrit pourtant, mais jusqu'à un certain point, l'élémentaire prudence, qui l'incite à se fondre à la communauté qui l'accueille. Doiron note à juste titre que tout voyageur est virtuellement un traître (p. 157), qui a la possibilité non seulement de mentir, d'embellir à grand renfort de captivantes narrations et de descriptions agréables ( $p .158$ ), mais au surplus de se retourner contre sa société en prenant le point de vue du peuple visité, "sauvage" ou non: le relativisme moral $\mathrm{du}_{\mathrm{xvII}} \mathrm{e}^{\mathrm{e}}$ siècle, on le sait, procède de cette attitude.

Topos bien connu des lecteurs de récits de voyage, l'épisode de la tempête en mer matérialise l'épreuve qui, en général, suit immédiatement le départ. "Rituel poétique marquant l'entrée dans la temporalité narrative du voyage" (p. 170), cet épisode "dramatise, en la projetant sur les mouvements de la nature, l'opposition fondatrice du genre, celle de l'errance et du "voyage bien ordonné et réglé" (p. 169). Les rituels du retour, enfin, répondent à ceux du départ et résolvent la dialectique classique du voyage et de la retraite, qui recouvre cet âge dans son entier, de Du Bellay à Voltaire. On reconnaît à celui qui revient le privilège sacré de la transfiguration, et son retour est, symboliquement, une apothéose, une parousie (p. 178). "La règle du retour au foyer écarte la menace du nomadisme, mais surtout illustre le mythe classique d'un retour à la pureté des origines" (p. 180), affirme Doiron; progrès et retour, voyage et retraite, caractérisent tant l'esthétique que la morale classiques. Le Cabinet du savant surmonte la dialectique en rassemblant dans un lieu clos la diversité du monde; et s'"il faut voir le Monde avant que d'en sortir" (La Mothe Le Vayer, cité par Doiron, p. 183), la retraite apparaît en définitive comme le véritable retour - à soi, à ses opinions, à sa terre natale.

Dans le mouvement qui va de la primauté des livres à celle de l'expérience conçue comme lecture du Monde passe donc l'essentiel de l'idéal classique, héritier de l'humanisme renaissant qui s'était défini, dans l'orbite de la sagesse antique, contre la 
118

pensée médiévale. Pour Rousseau, qui continue d'affirmer la précellence de l'expérience mais qui sait fort bien, par ailleurs, qu'il n'y a plus de contrées à découvrir, que la planète est désormais quadrillée par les signes (cartes et récits), l'âge des voyages semble dorénavant révolu, et l'humanisme du même coup. Aux Voyages autour du monde succède bientôt le Voyage autour de ma chambre de Xavier de Maistre (1794). Constatant l'utilité des voyages, mais les réduisant à une étape transitoire de la formation des jeunes gens, Rousseau réhabilite la promenade, déjà en faveur chez les péripapéticiens grecs et chez Montaigne, toutefois en la réinterprétant, comme les humanistes l'avaient fait du voyage antique. La promenade est occasion de rêverie hors du monde et des livres qui musellent la sensibilité, cèlent le moi profond. La vue, qui organisait le voyage classique, le cède à la vision préromantique: la voie est désormais frayée pour Nerval, Stendhal ("Je ne prétends pas dire ce que sont les choses, je raconte la sensation qu'elles me firent" - Rome, Naples et Florence en 1817 ) et les voyageurs du XIX siècle qui, plutôt que des mondes, découvriront d'insondables espaces intérieurs.

Robert Dion 